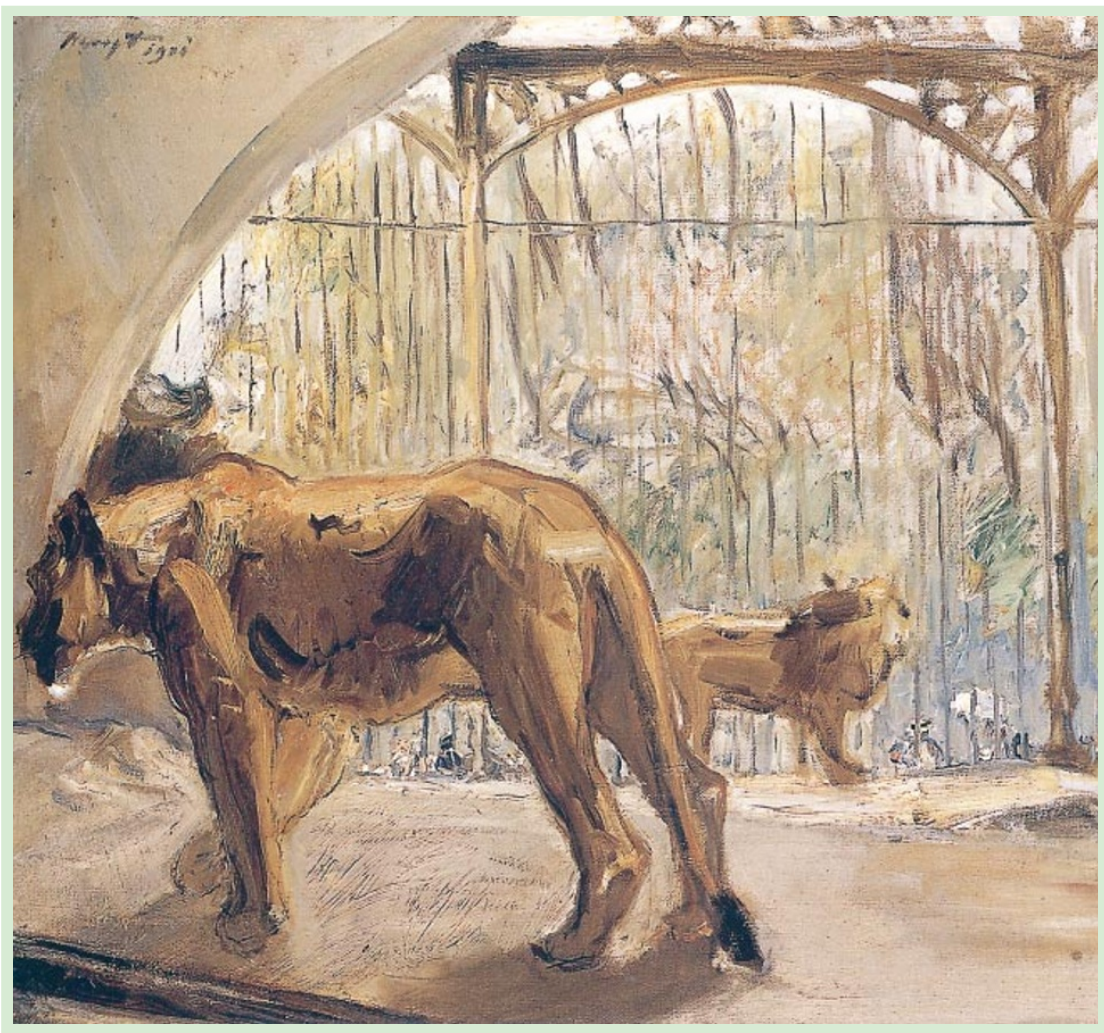

\section{Kept in captivity}

Lionesses Pacing in a Cage by Max Slovegt depicts the experience of wild animals put on public display. From Zoo: A History of Zoological

Many of the problems with Kettlewell's experiments and the 'classic' Biston story were first aired by the US biologist Ted Sargent. Curiously, when turning from Kettlewell to Sargent, Hooper's criticality evaporates. She claims that Sargent's criticisms of the moth work ruined his career by making him a pariah, rejected by a scientific establishment enamoured with Biston. But this is hyperbole. Sargent's career may have languished because he often published in little-known journals or (as Hooper notes) refused to apply for grants - the kiss of death for a US scientist.

Hooper also champions Sargent's view that industrial melanism was a case not of evolution but of "phenotypic induction" a developmental change in the colour of moths, presumably caused by the larval ingestion of pollutants. But she conveniently glosses over the simple and unassailable fact that the light and dark alleles of Biston segregate as mendelian variants when tested under uniform experimental conditions. Perhaps Hooper embraces the induction theory because it makes for a better story, but surely good science journalism demands that drama takes a back seat to data. Numerous scientific errors (the American peppered moth is not B. cognataria but $B$. betularia, the same species as in Britain,
Gardens in the West by Eric Baratay and Elisabeth Hardouin-Fugier (Reaktion Books,

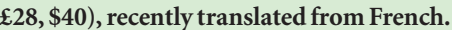

for example), mar the book for biologists.

The biggest shortcoming, however, is Hooper's failure to emphasize that, despite arguments about the precise mechanism of selection, industrial melanism still represents a splendid example of evolution in action. The dramatic rise and fall of the frequency of melanism in Biston betularia, occurring in parallel on two continents, is a compelling case of evolution by natural selection. No force other than selection could have caused such striking and directional change. Hooper's grudging admission of this fact occupies but one sentence: "It is reasonable to assume that natural selection operates in the evolution of the peppered moth."

This issue matters, at least in the United States, because creationists have promoted the problems with Biston as a refutation of evolution itself. Even my own brief critique of the story (Nature 396, 35-36; 1998) has become grist for the creationists' mill. By peddling innuendo and failing to distinguish clearly the undeniable fact of selection from the contested agent of selection, Hooper has done the scientific community a disservice.

Jerry A. Coyne is in the Department of Ecology 57th Street, Chicago, Illinois 60637, USA. and Evolution, University of Chicago, 1101 East

\section{Competition between women}

\author{
A Mind of Her Own: The \\ Evolutionary Psychology of \\ Women \\ by Anne Campbell \\ Oxford University Press: 2002. 402 pp.

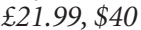

\section{Elizabeth Cashdan}

This provocative book argues that competition among women has been an important, yet largely ignored, force in human sexual selection. Competition between males is usually thought to be more intense than female competition because greater male variance in reproductive success means that men are playing for higher stakes. But Campbell suggests that this is misleading: "The variance may not be as great as between males but that is irrelevant because females are not in competition with males, they are in competition with other females." Mothers (not fathers) are critical to offspring survival, and differences among women in their success in this endeavour have shaped the way that women think, feel and behave.

The book opens with a sharp and satisfying critique of postmodernist biophobia and a skilful rebuttal to those who distrust evolutionary psychology's scientific methods and fear its political implications. It closes with an excellent in-depth account of the evolutionary reasons for individual variation. In between, Campbell shows us how and why women compete.

Women are clearly less physically aggressive and less risk-prone than men, but why? Campbell rejects the belief that it is a "default option that results from lower incentives for competition" and attributes it instead to women's greater parental investment: they have more to lose from violent and risky behaviour. This behavioural difference, she argues, is mediated by a sex difference relating to fear of injury and a neurochemistry that makes women better able to inhibit aggressive impulses.

These arguments are extended in Campbell's discussion of sex differences in dominance and status-seeking. The rewards of high status "are just as great for females as for males - arguably greater because resources fuel the survival of offspring in which they have already invested while for males it merely buys a ticket in the copulatory lottery of possible fatherhood", she argues. What differs, she continues, is not the rewards, but the costs (the risk of injury). This argument explains why women are less prone to seek high status through aggressive competition. It is also used to good effect in a later chapter on women and crime, in which Campbell explains why women commit 
fewer and less-violent crimes than men do.

But this fear of injury does not explain why women should actively seek egalitarianism, nor why they should form communal bonds with unrelated individuals that are more enduring and less exchangeorientated than the alliances formed by men. While most of the book is devoted to explaining how and why women compete, Campbell devotes a chapter to this more conciliatory side of female nature. She suggests that their communal tendencies are an evolved response to male philopatry, women's consequent lack of kin support, and the need for protection from men. Perhaps. It is a topic that deserves more attention from evolutionary psychology than it has received.
Many books discuss human sex differences from an evolutionary perspective, but this one differs from most as it is more a monograph than a text. Campbell has a point to make, and she integrates a vast array of material in doing so. That said, the book would nonetheless make a fine text for a graduate course on the evolutionary psychology of women. Among the book's strengths are its emphasis on conditional strategies, its integration of 'ultimate' (adaptive) and 'proximate' (neurological and biochemical) levels of explanation, and its authoritative treatment of female aggression - a field in which Campbell has done considerable ground-breaking research. Notwithstanding its specialized focus, it does cover the bases in the evolutionary psychology of human sex differences, and the treatment is thorough, thoughtful and up-to-date. The writing is also clear and engaging.

My pleasure in reading the book was repeatedly marred, however, by the publisher's treatment of the references. They are grouped by chapter at the end of the book (rather than being listed alphabetically), and it is a guessing game to find the chapter you need. If references must be grouped this way, please give readers a hint about where to look by indicating the chapter title at the top of each page of references.

Elizabeth Cashdan, Department of Anthropology, University of Utah, Salt Lake City, Utah 84112-0060, USA.

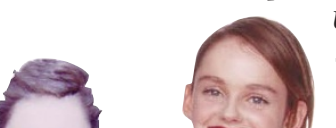
.

\section{Science in culture}

\section{Natural style}

Ideas taken from science are proving to be fashionable.

David Cyranoski

Like the criss-cross pattern of a sunflower head and the spiral of a nautilus shell, Eri Matsui's best-selling wedding dress (above, far right) can be described using the Fibonacci mathematical sequence. The Japanese fashion designer used increasingly short layers of fabric in the skirt to form sections in a $1,1,2,3,5,8,13,21,35, \ldots$ pattern, culminating in 56 narrow tufts around the waist. "People recognize the beauty in the order, whether they are looking at the dress or wearing it," says Matsui, who has devoted herself to finding universal forms to make women look beautiful.

Having experimented with images from knot theory, fractal models and Klein bottles, Matsui has more recently been scouring the world of biology for universal forms to use. Her November 2000 collection, for example, with the theme "Brain, Mind, Computer, and Fashion", showcased dresses with colourful images of neurons and others whose thick folds approximate the brain's contours (above in lilac).

Best known in Japan for her somewhat unconventional wedding dresses, Matsui knows that these kinds of design are unlikely to become

\section{a common sight on the streets of Tokyo or} in wedding halls. "But these designs help open up the imagination, and provide a basis for designing more practical clothing for everyday wear," she says. Practical clothing based on universal forms does not have to be conventional, she insists.

For her last collection, entitled "A Changing Erotic Lifeless Object”, shown on 18 April, Matsui tailored several sets of clothes around cell division and differentiation. In one series, the first model emerged onto the catwalk totally enshrouded in an egg-shaped netting. The next, with netting billowing out above and below a tight waistline, was undergoing the first stage of cell division. The series continued with representations of multiple cell stages. Another series (above, left five images) began with straight horizontal lines representing a single cell that gradually curved, model by model, becoming increasingly individual and specialized. The series ended with a death stage, in which slits represented cell walls breaking apart.

Matsui hopes that her work will help us to realize what we are, and recognize the beauty

$$
\text { . }
$$

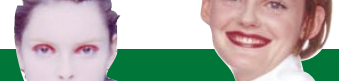

